\title{
THE ROLE OF NATURAL TOURIST RESOURCES FOR BULGARIA'S TOURISM REPUTATION
}

DOI: http://dx.doi.org/10.18509/GBP.2018.31

UDC: 338.483.11(497.2)

\author{
Dora Kabakchieva \\ Vanya Vasileva \\ Sevdzhan Sabrieva \\ Mariana Angelova \\ Konstantin Preslavsky University of Shumen, Bulgaria
}

\begin{abstract}
:
The reputation of the territory is based above all on the territorial individuality, which consists of (1) the identification features of the site and (2) the set of its distinctive features and resources. Natural tourism resources, as an important part of this totality, contribute significantly to the formation of the reputation of the territory. More than two-thirds of the trips are directed to these resources. Therefore, they can be decisive.

Bulgaria's natural tourism resources are varied and specific. Their peculiarities are determined by the location of the country in temperate latitudes along the fringe of the subtropics and bordering the Black Sea and the Danube. Having many mountains is also important for Bulgarian tourism and for shaping the tourist image of Bulgaria.

The purpose of the paper is to analyze the use and to determine the importance of Bulgaria's natural tourism resources for the formation of the country's tourist reputation. The essence of such an issue is closely related to the opportunities, efficient exploitation and realization of the potential of these resources, on the one hand, and the establishment of a beneficial, active and consciously managed reputation in the tourist territory, on the other hand.
\end{abstract}

Key words: reputation, natural tourism resources, Bulgaria

\section{INTRODUCTION}

If the attractiveness of one or another place, territory, site was originally predetermined by the natural properties and qualities of its adjacent resources, it is now maintained by the positive tourist image of the place, the good reputation created over a long period of time, established in the consumer's - mind as a brand. "The tourist image is a symbol of the tourist potential of the place (locality, settlement, region, country)" [6]. Because of this, the tourist image can "be seen as an extremely important resource for raising the prestige of the place ..." [6]. In Krastev's interpretation, the advantages of the tourist landscape - and in particular the natural and anthropogenic tourism resources - have made a significant contribution to the formation of the tourist image of the site. "By accumulating a certain emotional-psychological charge, images become an irrevocable attribute of identity that influences the formation of "territoriality" in people's lives and whose reputation depends on one of the main intangible assets of space to maintain competitiveness in its development" [7]. Natural tourism resources are a "subsystem of the territorial system of recreation and tourism" [8]. Therefore, they are a subject of attention of the geography of tourism. Apostolov's review of the relevant literature in this 
regard [2] shows that tourism resources are mainly viewed in connection with tourist activities and the tourist product, and that they are mainly surveyed in older publications. Their importance for the formation of the tourist image and the reputation of a destination has been considerably less studied but increasingly relevant in the conditions of increased competition between destinations in the tourism industry.

The purpose of this publication is to analyze the role of Bulgaria's natural tourism resources in improving the country's tourism reputation. The essence of such an issue is closely related to the opportunities, efficient exploitation and realization of the potential of these resources, on the one hand, and the establishment of a beneficial, active and consciously managed reputation in the tourist territory, on the other.

The focus of the survey is Bulgaria as a tourist destination. The aim of the study is the natural tourism resources as a basis for the formation of the country's tourist reputation. The methodology includes use and presentation of results of conducted surveys. Both secondary and primary sources of information are used. Through the analysis, synthesis, induction and deduction the results of the conducted survey were received and presented.

\section{REPUTATION OF THE TERRITORY}

The reputation of one territory is based primarily on the territorial individuality, which consists of (1) the identification features of the site and (2) the set of its distinctive features and resources:

1. The external identification features of the territory form a totality of visual, verbal and other indications determining its identity (geographical location, belonging, name, distinguishing signs - coat of arms, flag, anthem etc.). They produce a "passport" with all the necessary data to prove its identity. It is imperative that the approaches to shaping identifying elements are seriously considered and targeted.

2. The set of distinctive features and resources of the territory is objectively built and combines:

- natural, demographic, historical, social and cultural features - natural and climatic conditions and raw materials, human factor, standard and quality of life, social policy and social infrastructure, cultural and historical heritage, etc .;

- economic specifics - degree of development of the economy, production infrastructure, human resources, availability of skilled labor and employment, investment potential and innovative capabilities, financial resources, business activity level of safety for businesses, etc .;

- Organizational-legal and communication characteristics - level and quality of management, information services and technologies, communication features, communication policies, advertising market and PR services, institutional capital, legislation, efficiency of state policy and power, etc.

The beliefs and attitudes of the people that arise in relation to precisely the territorial personality form the reputation of the territory - that is, the territorial identity is the basis on which this strategic phenomenon is built and managed. The subjective notions of the territory arise as a result of immediate personal experience (permanent or temporary residence) or through mediated impressions (in the words of eyewitnesses, media, art works, etc.).

The communication aspects of tourism activity concern, on the one hand, its effective and high quality information provision and, on the other, the establishment and maintenance of the reputation of both the whole sector and each of its structural units and constituents. 
The information tourist resources contain data about the material objects located in a certain tourist area or included in a specific tourist product or destination - about the historical, artistic or cognitive values owned by these objects, about their natural geographic characteristics and peculiarities, about the related stories, legends and myths, their dedicated research, etc. The tourist information resources refer not only to the verbal information but also to the various material collections expositions and exhibits and, of course, the people who produce and serve these information facts in order to be professionally, adequately and attractively offered to interested groups. Potential users are informed about their travel opportunities by using current promotional systems (brochures, guidebooks, maps, catalogs, etc.)

The main tasks for providing information on the evaluation of tourism potential are:

- forming a positive opinion about the tourist resources of the territory;

- support for the formation of competitive tourism products;

- assistance in developing programs and projects in the field of tourism;

- an analysis of the economy and infrastructure of the relevant tourist region;

- creation of information and promotional materials;

- organizing special events to promote and impose a positive reputation on the territory, etc.

The creation and transfer of positive sustainable knowledge and perceptions of the tourist territory and ensuring its acceptance by the stakeholders is a major task of reputational management in tourism, implicitly related to the specifics of consumer's behavior in this sector:

1. Until the tourist trip is carried out, the reputation of the relevant area for the potential tourist is based on the information he/she receives and the disseminated persistent notions of its distinctive properties distinguishing it from the other similar territories. Therefore the reputation is one of the key factors determining the choice of the consumer.

2. After the end of the trip, reputation is already based on the immediate perceptions of the tourist and develops as a collection of his/her emotional and rational ideas, formed by the reflection of his own life experience and value system. The judgments and opinions of people who have personal experience of the territory, its distinctive and unique features determine its attractiveness or unattractiveness to the next consumer as well as the degree of its popularity.

The understanding of these two general approaches (indirect and direct) in the argumentation of reputation allows its purposeful management as a unique strategic asset in the field of tourism. This requires adequate communication policy at national and regional level, which is the priority and responsibility of the management in tourism administrations and organizations.

The reputation of one territory is based primarily on the territorial individuality, which is composed of the identification features of the site and the combination of its distinctive features and resources. In this sense, the natural resource potential is a characteristic indicator and a factor in the establishment of the respective reputation, and the measures taken for its study, conservation, absorption, transformation and rational use determine the potential of this territory for development and tourism. [5] 


\section{PLACE OF NATURAL TOURIST RESOURCES IN THE TOURISM SYSTEM}

The tourism system is a combination of tourism-resource potential of the territory, tourists and the tourism industry. These components are constantly changing and modifying [4], which makes tourism a highly dynamic phenomenon.

Each tourist area is formed on the basis of a specific combination of many factors and quality characteristics. On the one hand, it tolerates the interaction of an external environment, national and / or international, consisting of political, economic, legal, cultural, ecological, etc. conditions, changes and trends. On the other hand, the territory is influenced by local (domestic) political, economic, productive, social, and other circumstances. A central place among its structural elements occupies the tourism resources, which are the main reason for the attractiveness to tourists (natural-geographic, cultural-historical and socio-economic facts). The rest of its components are secondary, derived conditions - accessibility, infrastructure, institutional environment, conditions of stay, price, etc. Reputation is the unifying link in this mix because it depends on how interested groups will appreciate and perceive the territory, how its values, benefits, and advantages will be communicated.

The resource potential of the territory is a set of all resources - both included in the processes of public reproduction and the potential to participate in it. The modern transformation of the economy of the regions and the necessity to maximize the use of the existing elements of nature determine the relevance of the research of the potential of the tourism resources as a significant factor for the socio-economic development of the territory. The study of tourism resources is based on ambiguous approaches and definitions of the baseline concept. The linkage of tourism with geography is reflected in the terminology. Initially, tourism resources are traced naturally and geographically, and their study is limited to assessing the landscape environment for recreation and tourism. Interdisciplinary studies complement and broaden this viewpoint on a social level. Thus, the conditions for accessibility, facilities and comfort, attractiveness of cultural and historical, recreational and other tourist activities are added to the natural environment for vacation. Today all resource factors are considered in direct connection with the other parameters of tourism - their suitability for the processes and purposes of tourism, the possibilities for using them to enhance its development, the development of tourism products and services, etc.

The inclusion of tourism in market relations necessitates an in-depth study of the different organizational, economic and social aspects of the management mechanisms of tourism resources, state and regional regulation issues, as well as the specificities of these resources and related activities. The growth of the tourist activity of the population and the commissioning of new natural and other resources predetermine the need to systematically study the opportunities for purposeful and constant management of communication processes with a focus on establishing a sustainable positive reputation of the territory.

The definition of natural tourism resources is invariably related to their specific features - non-transferability, the impossibility of moving from one place to another in order to take part in a particular economic activity. From the positions of regional tourism, this commitment is important because natural resources are limited and their existence is directly dependent on the economic condition of the territory. The possibilities for meeting the needs of tourists are directly related to the content and status of the resource factors of the territory on which the region is located. All this influences the definition of tourism resources: a set of natural climate, socio-cultural and infrastructure factors in the 
territory used in the construction of tourism products to meet the needs of the people and the objectives of tourism.

A necessary condition for the development of tourism is the availability of tourism potential on the territory. Managing this potential is a leading prerequisite for forming an attractive tourist product and a desired tourist destination. Most often, the term "tourist potential" reflects the economic nature of tourism and, accordingly, the sum of the resources, conditions and means necessary for its realization. The resource base of tourism potential is composed of the natural, cultural, historical, infrastructural, labor, information, etc. wealth and opportunities of the region in their entirety and interdependence. There are several approaches for assessing the existing basis:

- quantitative assessment - quantitative description of existing resources, determination of their volume and stocks;

- qualitative assessment - allows optimization of the use of resources on the territory;

- analysis of potential opportunities - determination of the scope of operation and exploitation, calculation of the economic, social and environmental impacts of the activity.

- The common approach to assessing the resource base of tourism potential is the pressing need to process and create large data bases.

- The assessment of the tourist potential of the territory is in line with the three main groups of factors in tourism:

- generating (needs-related);

- realizational (resource-related);

- localizing (related to population awareness).

For the purpose of this study, it is appropriate to pay special attention to localizing factors because they are designed in the management of communications in tourism. The effect of these factors is the organization of communication processes and information provision, the imposition of communication standards on tourist services, the creating attractive tourist images, the sustainable reputation of the tourist territory / product / organization and of active tourist brands. From the point of view of the tourism potential, we are talking about the maximum complete and targeted awareness of the interested parties about the existing opportunities for tourism (organization and conduct) within a certain territory. Leadership plays a role both in the overall natural environment and in individual remarkable elements (natural tourism resources). The activation of localizing factors and their expert administration are able to weaken, correct or direct the action of the other groups (generating and realizing), so they are particularly important and are becoming more and more firmly established in the heart of the management efforts in the tourism industry.

\section{SIGNIFICANCE OF BULGARIAN NATURAL TOURISM RESOURCES FOR FORMING THE TOURIST REPUTATION}

Natural tourism resources, as an important component of the tourism system, contribute significantly to the formation of the reputation of the territory. More than two-thirds of the travel trips have been reported globally [3]. Therefore, they can be even decisive in this respect.

Bulgaria is a European, Balkan, Black Sea and Danube country. The country's natural tourism resources are varied and specific. To a large extent, their peculiarities are determined by the location in the moderate latitudes of the subtropical border, which 
predetermines the specifics of climate, vegetation and landscapes. Having many mountains is also important for Bulgarian tourism and for shaping the tourist image of Bulgaria. Here is the highest mountain on the Balkans - Rila with Musala peak (2925 m). Undoubtedly, the most exploited natural tourist resource is the Black Sea. Most foreign tourists associate Bulgaria with the Black Sea coast and remain unfamiliar with the interior of the country. While the location in the European tourist region is rather a favorable prerequisite for the formation of positive ideas, the same can not be said about our location in the Balkans.

The representative study Attitudes of EuropeansTowardsTourism [11] examines different aspects of Europeans' tourist behavior and motivation. The report was prepared on the basis of a large-scale survey. The paper also focuses on aspects of natural tourism resources. The study finds that $26 \%$ of the Europeans' chief motif of visiting is nature (mountains, lakes, landscapes, etc.). For another $40 \%$, the main motivation for taking a trip is the sun (weather conditions) and beaches. Therefore, a total of $66 \%$ or $2 / 3$ of European citizens' trips are due to motives related to natural tourism resources. On the other hand, anthropogenic tourism resources concentrated mainly in cities and represented mainly by cultural landmarks provoke $44 \%$ of the trips. Therefore, natural tourism resources have a leading position in this respect. Nature is the most important for the citizens of the Netherlands $(42 \%)$ and the least attractive for the Irish $(8 \%$, for Bulgaria $-22 \%$ ). The beaches and the climate are the most attractive to the citizens of Luxembourg $(58 \%)$ and Slovenians (58\%), and the least important for the Maltese (11\%, for Bulgaria $-39 \%)$.

Nature (climatic conditions, landscape) is also an important factor for turning tourists into regular visitors. 50\% of European citizens have named them as a determining factor in this respect, the same number applies to Bulgarians. Compared to the other factors making the visitors loyal customers (accommodation, pricing, etc.), the natural assets stand out as leaders. They are most important for the loyalty of the Czechs (65\%) and the Netherlanders (65\%), and the least relevant to the Macedonians (24\%).

A more specific expert assessment of tourism (including natural tourism resources) makes the World Economic Forum in the Travel and Tourism Competitiveness Report 2017 [14]. On the scale of 1 to 7 our country's natural tourism resources are estimated at 3.8. By this criterion, we are ranked $41^{\text {st }}$ among the 136 countries concerned. This rating is lower than the average estimate for tourism in our country $\left(4.1,45^{\text {th }}\right.$ position). But according to this criterion, Bulgaria is placed ahead of the same ranking in 2015. Therefore, a trend towards improving the outcome is reported. A number of other factors received higher estimates, factors such as health and hygiene $(6,6)$, tourism services infrastructure $(5,8)$, price level $(5,3)$, safety and security $(5,1)$. Therefore, the natural tourism resources of our country, which are often a reason for national pride, are not considered by international experts as leading competitive advantages for Bulgarian tourism. On the contrary, the results speak about their mediocre role in shaping Bulgaria's attractiveness in the eyes of the foreigners. It is interesting to find out why this assessment is not high and how the international experts, who use the following criteria, justify themselves [14]:

- the number of natural sites in the UNESCO World Heritage List. For Bulgaria - 2 sites, $30^{\text {th }}$ position among the countries concerned;

- Biodiversity (number of known species). For Bulgaria - 448 species, $82^{\text {nd }}$ position;

- share in $\%$ of the protected areas in the country. For Bulgaria $-40.5 \%, 5^{\text {th }}$ position in the world; 
- opportunities for digital search for natural tourism. For Bulgaria - 24 (scale from 0 to $100), 42^{\text {nd }}$ position;

- Attractiveness of the natural environment. For Bulgaria - rating 5, $76^{\text {th }}$ position;

A significant increase in the rating is accounted for by the increase in the share of protected areas, as well as the attractiveness which is assessed higher than the 2015 rating. The environmental quality assessment is likely to be low, probably due to the strong anthropogenic changes during the centuries, which is typical of the European continent. Biodiversity also scores poorly, but it is not clear how it is defined with only 448 species. The share of protected areas is the most valued due to the large number of international agreements in which our country participates, under which more than one third of the territory is under a different way of protection.

Based on the results of the studies presented above, it can be summarized that:

- natural tourism resources are a determining motif for tourist trips;

- Bulgaria's natural tourism resources are not highly valued by foreign experts, which can be seen as a limiting factor for the incoming international tourism to our country. Positive is the fact that Bulgaria appears more and more frequently in a number of world rankings with tourist orientation, and in some cases whole publications are dedicated to our country . For example, in the April 18, 2017 issue, British Telegraph (cited by http://www.economic.bg) [12] published an article, which cited 19 reasons to visit Bulgaria. These include the beaches, the incredible mountains, the Pirin and Rila national parks, the opportunities for ski tourism and the observation of bears in their natural environment, the Belogradchik Rocks and the caves. The area around Mount Musala is defined as a paradise.

In 2016, there are two Bulgarian representatives in the ranking of Top 10 spiritual places in the world with a strong energy emission [13]. No. 1 is Rila , ahead of Machu Picchu in Peru, Uluru Plateau in Australia and others. No. 6 is Belintash, which is ahead of Stonehenge and even Tibet.

Such publications are important for the tourist reputation of our country and contribute to the imposition of certain tourist images and brands.

A series of studies conducted by Vasileva [9] [10] investigates what tourists associate Bulgaria with:

- in case of a free answer, every fifth Bulgarian respondent associate the Bulgarian nature with the Black Sea and its coastline, and one in every 16 associates it with the mountains. For every eleventh, the mountain lakes and, in particular, the Seven Rila Lakes are most clearly visible. The National and Nature Parks, and in particular the Pirin National Park, the Rila National Park, the Central Balkan National Park or the Strandja Nature Park are pointed out by one in 23. Other emblematic natural sites with which the respondents associate the Bulgarian nature are the caves, namely Prohodna and Magura (3,4\%), as well as Musala peak (2,6\%), Srebarna lake (2,6\%), Belogradchik rocks, Wonder Rocks, Stone Wedding, Cape Kaliakra, Paradise Praskalo, Krushuna Waterfalls, etc. [9]

- A similar survey among Polish citizens highlighted several major associations:

- - seaside resorts - Golden Sands, Nessebar, Balchik, Varna, Sunny Beach;

- - sea, warm sea, the Black Sea, the Black Sea side are the marine themes;

- - tourist emblems - warm climate, delicious cuisine, Shopska salad, grapes, rakia, good wine, Bulgarian music and folklore, arts, holidays, festivals;

Some of the respondents relate Bulgaria to reasonable prices, as well as to neighboring Romania. 
It can be noticed that almost all associations are directly or indirectly related to tourism and mainly to the marine tourism resource. Therefore, it can be reasonably concluded that the Polish people associate Bulgaria with tourism on the Black Sea coast. On the one hand, it is positive that the Poles obviously have a vision for our country. On the other hand, however, this vision is limited only to the Black Sea coast and to the classic maritime tourist product. There are no answers to connect Bulgaria with sites and sights from the interior of the country, with cultural and historical sites and places or other tourist attractions besides the sea and the cuisine.

It is well known that most Europeans associate Bulgaria with the Black Sea, but Japanese tourists, for example, associate it with the oil-bearing rose. It would be useful to make similar surveys on associations in all major emitional tourism markets in Bulgaria.

\section{CONCLUSION}

The reputation of a territory (country, region, destination) is not simply the result of a PR campaign or other communication techniques, but is formed by the actual facts, merits and achievements of this territory, and the correct, purposeful communication in this respect . Reputation management is a prerogative and commitment of the institutions and authorities, tour operators and agencies to the cultural and sporting structures operating in the region and having a sustainable positive interest in it. In order to optimize this strategic process, it is necessary to focus our attention on those aspects of the reputation that at this moment cause the greatest interest in the target groups - ie. to determine who / what lies in the heart of the reputation for each of them - the natural-climatic features, the history, the socio-economic indicators, the cultural artifacts, the famous persons, etc. In this sense, natural tourism resources are an important component of the reputation and could (depending on the interests and opportunities) become a unifying center of a wellthought-out and coordinated strategy. For such a strategy to be effective, it needs to be based on precise and clearly defined focus points. In practice, this is rather complicated and requires serious experts and resources. That is why, in most cases as the Bulgarian practice shows, unsystematic messages and data in the form of advertising, descriptions of investment projects, complex brochures and albums, which are limited to the most general characteristics of the territory, are seldom updated and instead of supporting the reputation - on the contrary, they cause a negative attitude. In Bulgaria, research and stakeholder analysis are rather incidental (for the purposes of individual institutions, manufacturers and traders), have limited scope and are aimed at solving a specific problem. Any attempt to deepen those processes that are relevant to the reputation of the territory, however modest it may be, would at least lead to the specification of expectations and attitudes.

Bulgaria is becoming more international with its combination of natural and cultural heritage, a rich and attractive network of natural and cultural resources. It is a well-known and preferred tourist destination with a clearly recognizable national identity, preserved nature and culture. Natural tourism resources are an important part of the development of tourism and to a great extent they are decisive for forming the reputation of our country as a tourist destination. More than half of the tourist trips in Bulgaria are directed to the sea and mountain resorts. Namely the sea and mountain tourist resources are the attraction center for most of the foreign and Bulgarian tourists. These resources are also important for shaping the image of established and leading tourist resorts in our country such as 
Golden Sands, Sunny Beach, Albena, Varna, Bourgas, Nessebar (for development of sea tourism) and Pamporovo, Bansko, Borovets (for winter and ski tourism).

Natural tourism resources are leading in the formation of tourism products for the development of some alternative forms of tourism: ecological, mountain, ornithological, natural-cognitive, rural, adventure, wine, sports and others. According to numerous studies conducted at home and abroad, natural tourism resources are decisive for shaping tourist attractiveness and are of paramount importance in shaping the image of Bulgaria as a tourist destination. Unfortunately, they are still insufficiently used to improve Bulgaria's reputation, and in some cases even compromise the country's good name and tourist image. Creating a sustainable reputation for one territory takes decades. Its destruction, on the one hand, is difficult due to the cultural depth and stereotype sustainability but, on the other hand, it is easily accessible due to the virtually unlimited and uncontrolled information flows.

In order to improve the reputation of Bulgaria using its natural tourism resources it is necessary to:

- maintain and improve the state of the environment;

- preserve the natural heritage;

- preserve biodiversity and stimulate economic growth;

- exercise strict control on the status of beaches and sea water along the Bulgarian Black Sea coast;

- implement a comprehensive environmental policy for enhancing the ecological awareness of both local communities and tourists;

- explore the expectations and the satisfaction of tourists from the major tourism markets;

- study targeted and coordinated advertising-information publications for tourism, which correspond to the expectations of specific target groups;

- Participate in tourism fairs in the country and abroad with a focus on the types of tourism developed mainly on the basis of the natural-resource potential;

- realize joint programs and initiatives between municipal and non-governmental organizations for popularization of tourism in the different regions of the country;

- greater control by local authorities to limit the environmental impact of tourism.

Tourism reputation can not be constructed, it is worthwhile - "the way to achieve a better reputation is to make efforts for what you want to see" [1]. A key goal in reputation management is the valuation of something unique and different, which can bring the tourist territory to others and highlight it as the only one of its kind. The diversity of natural resources in Bulgaria clearly demonstrates that there is a wide scope for creative realization.

\section{REFERENCES}

[1] Anholt, S. Place, Identity, Image and Reputation. Macmillan N.Y., pp 5-6, 2011.

[2] Apostolov, N., Geography of tourism - a century of development and achievements, Bg, pp 283-310, 2013

[3] Apostolov, N., I. Markov, Tourist resources, Bg, pp70-73, 2015

[4] Cooper, C. \& J. Fletcher D.\&Gilbert S. \&Wanhill. Tourismprinciplesandpractice, UK, pp 194, 2005.

[5] Kabakchieva, D., Reputation Management in Tourism, Bg, pp , 2017 
[6] Krystev, V., The tourist image of the place: theoretical and practical-applied aspects, $\mathrm{m}$. Geography problems, Bg, vol. 3-4, pp 139-152, 2014.

[7] Krystev, V., Tourist image of space as indicator of "soft power": a geopolitical assessment on the example of Bulgaria, m. Geography problems, Bg, vol. 1-2, pp 71-82, 2017.

[8] Popova, N., Natural recreational resources, Bg, pp , 1993

[9] Vasileva, V., Natural tourism resources of Bulgaria, Bg, pp 309, 2018

[10] Vasileva, V., The Polish Tourist Market, Bg, pp 108-109, 2012

[11] Attitudes of Europeans Towards Tourism, pp 7-80, 2013

[12] http://www.economic.bg

[13] http://www.theearthchild.co.za/top-10-spiritual-places-on-earth/

[14] https://www.weforum.org/reports/the-travel-tourism-competitiveness-report-2017

Project №: РД-08-160/9.02.

2018 „Promoting knowledge in geography, regional policy and tourism“, Shumen University 